\title{
DAMPAK KEPEMIMPINAN NEHEMIA DAN RELEVANSINYA DENGAN GEREJA-GEREJA DI JAWA TENGAH
}

\author{
Sentot Purwoko, ${ }^{1}$ David Ming, ${ }^{2}$ Christian Ade Maranatha ${ }^{3}$ \\ Sekolah Tinggi Teologi Kadesi, Indonesia ${ }^{12}$ \\ Sekolah Tinggi Teologi Widya Agape, Indonesia ${ }^{3}$ \\ Email: davidmingming3@gmail.com ${ }^{3}$
}

\begin{abstract}
The church in terms of organization and communication systems cannot be separated from the leadership of God's servants, because leaders have an influence on the growth and development of the organization in the church. The role of a successful leader in organization and communication is critical. The formulation of the problem posed by the author is: the success of implementing leadership based on the book of Nehemiah for God's servants in churches throughout Central Java? Is the character of dependence on God the most dominant character modeled by God's servants in churches throughout Central Java? Which background category is the most dominant in determining the success of implementing the leadership of God's servants based on Nehemiah's book for God's servants at GKKI throughout Central Java. The author uses a quantitative descriptive method with an explanation method for the type of correlation review. Is the successful implementation of leadership based on the book of Nehemiah for God's servants in churches throughout Central Java in the sufficient category? Is the dimension of depending on God as Nehemiah's most dominant character in the role modeled by God's servants in churches throughout Central Java in carrying out successful leadership based on the Book of Nehemiah proven true?
\end{abstract}

Keywords: Successful Leader, Nehemia Leadership, The Churches of Central Java

\begin{abstract}
Abstrak
Gereja dalam pengertian organisasi dan sistem komunikasi tidak dapat dipisahkan dari kepemimpinan hamba-hamba Tuhan, kerena para pemimpin mempunyai pengaruh terhadap pertumbuhan dan pengembangan organisasi di gereja. Peranan pemimpin yang berjaya dalam organisasi dan komunikasi sangat penting. Rumusan masalah yang ditimbulkan oleh penulis adalah: keberhasilan pelaksanaan kepemimpinan berdasarkan buku Nehemia untuk hambahamba Tuhan di gereja-gereja di seluruh Jawa Tengah? Apakah watak bergantung pada Tuhan merupakan watak paling dominan yang dimodelkan oleh hamba-hamba Tuhan di gereja-gereja di seluruh Jawa Tengah? Kategori latar belakang mana yang paling dominan menentukan keberhasilan pelaksanaan kepemimpinan hamba-hamba Tuhan berdasarkan buku

Nehemia untuk hamba-hamba Tuhan di GKKI di seluruh Jawa Tengah. Penulis menggunakan kaidah deskriptif kuantitatif dengan kaidah penjelasan jenis tinjauan korelasi. Apakah pelaksanaan kepemimpinan yang sukses berdasarkan kitab Nehemia untuk hamba-

hamba Tuhan di gereja-gereja di seluruh Jawa Tengah berada dalam kategori yang mencukupi? Apakah dimensi bergantung kepada Tuhan sebagai watak Nehemia yang paling dominan dalam peranan yang dimodelkan oleh hamba-hamba Tuhan di gereja-gereja di seluruh Jawa Tengah dalam melaksanakan kepemimpinan yang sukses berdasarkan Kitab Nehemia terbukti benar?
\end{abstract}

Kata Kunci: Pemimpin Sukses, Kepimpinan Nehemia, Gereja-Gereja Jawa Tengah 
PENDAHULUAN

George Barna mengatakan, "Kepemimpinan adalah mengerahkan orang lain menuju satu tujuan yang diperjuangkan bersama-sama oleh pemimpin dan pengikut-pengikutnya."1 Ini berarti pemimpin harus mampu mengarahkan dan mempengaruhi orang lain kepada tujuan atau sasaran yang akan ditujunya. Sedangkan Agus Lay mengutip pendapat P. Oktavianus yang mengatakan "Kepemimpinan ialah keseluruhan tindakan, sikap dan tingkah laku seseorang (pemimpin) dalam mempengaruhi, menggerakkan dan mengarahkan orangorang lain untuk melaksanakan seperangkat kegiatan secara efektif, demi mencapai tujuan yang telah ditetapkan."2 Untuk mengenali tipe kepemimpinan kita akan melihat bebrapa tipe yang didiskripsikan dibawah ini.

\section{Tipe Paternalistik}

Untuk mengetahui tipe pemimpin Paternaslitik, untuk itu perlu mengetahui pengertian Paternaslitik berasal dari Kamus Besar Bahasa Indonesia. Arti kata "paternalis" menurut Kamus Besar Bahasa Indonesia adalah "sifat kebapaan."3 Ini

\footnotetext{
${ }^{1}$ George Barna, Kepemimpinan - Leaders On Leadership (Malang: Gandum Mas, 2002).

${ }^{2}$ P. Oktavianus, Manajemen Dan Kepemimpinan Menurut Wahyu Allah (Malang: Gandum Mas, 1988), 2

${ }^{3}$ Tim Penyusun Kamus Pusat Pembinaan Dan Pengembangan Bahasa, Op.Cit., 736.
}

berarti bahwa tipe pemimpin paternalistik memberikan penjelasan hubungan antara atasan dengan bawahan memiliki sifat hubungan kebapaan atau dengan kata lain tipe paternalistik bersifat informal. Pemimpin dengan tipe paternalistik memiliki ciri antara lain sebagai berikut:

(1) Pemimpin bertindak sebagai seorang bapak, (2) Memperlakukan bawahan sebagai orang yang belum dewasa, (3) selalu memberikan perlindungan kepada para bawahan yang kadang-kadang berlebihan, (4) Keputusan ada di tangan pemimpin, bukan karena ingin bertindak secara otoriter, tetapi karena keinginan memberikan kemudahan kepada bawahan. Oleh karena itu para bawahan jarang bahkan sama sekali tidak memberikan saran kapada pimpinan, dan Pimpinan jarang bahkan tidak pernah meminta saran dari bawahan, (5) Pimpinan menganggap dirinya yang paling mengetahui segala macam persoalan. ${ }^{4}$

Berdasarkan pendapat tersebut, pemimpin dengan tipe Paternalistik lebih cenderung memanjakan bawahan. Seorang pemimpin dengan tipe Paternalistik memandang bawahan sebagai seorang yang belum dewasa baik dalam tindakan maupun dalam pikirannya. Dengan demikian seorang pemimpin perlu membimbing dan menuntun bawahan secara terus menerus.

\footnotetext{
${ }^{4}$ Wursanto. Dasar-Dasar Ilmu Organisasi (Yogyakarta: Andi, 2002), 202.
} 


\section{Tipe Karismatik}

Pemimpin dengan tipe karismatik seringkali membuat kagum bawahan. Pemimpin dengan tipe karismatik memiliki daya energik lebih dan berwibawa dalam mempengaruhi orang yang dipimpinnya. Secara teori tipe pemimpin karismatik menurut Wursanto bahwa:

Seseorang menjadi pemimpin karena mempunyai karisma (pengaruh) yang sangat besar. Karisma itu diperoleh dari Kekuatan Yang Maha Kuasa. Dalam hal ini ada suatu kepercayaan bahwa orang itu memiliki kekuatan dari Tuhan sehingga dianggap mempunyai kekuatan ghaib (supranatural power). Pemimpin yang bertipe karismatik biasanya memiliki daya tarik, kewibawaan dan pengaruh yang sangat besar. ${ }^{5}$

\section{Kepemimpinan karismatik} memberikan suatu petunjuk bahwa sifat dan kepribadian yang kuat dan menarik dari seorang pemimpin. Biasanya seorang pemimpin yang karismatik memiliki karisma yang sangat menonjol dalam hal kepribadian dan kemampuannya, hingga karismanya tersebut dapat mempengaruhi orang-orang yang dipimpinnya.

\section{Tipe Demokratik}

Menurut Adam Ibrahim Indrawijaya sebagaimana dikutip oleh Wursanto bahwa "Gaya kepemimpinan

\footnotetext{
${ }^{5}$ Wursanto. Dasar-Dasar Ilmu Organisasi, 199.
}

demokratis pada umumnya berasumsi bahwa pendapat orang banyak lebih baik dari pendapatnya sendiri dan adanya partisipasi akan menimbulkan tanggung jawab bagi pelaksananya." 6 Pemimpin dengan tipe demokratik adalah bentuk kepemimpinan yang didambakan. Meskipun terdapat kelemahan dan kekurangan pada pribadi pemimpin, tetapi pemimpin yang demokratik tetap dipandang sebagai tipe kepemimpinan terbaik. Dalam kepemimpinan demokratik seorang pemimpin memandang peranannya sebagai seorang koordinator dan integrator sehingga seorang pemimpin bergerak sebagai suatu totalitas yang memimpin. Tipe kepemimpinan demokratik pada saat mengambil keputusan menyertakan bawahan untuk ikut serta memikirkan keputusan tersebut sebab hal tersebut merupakan rasa tanggung jawab, maka seorang pemimpin yang demokratik perlu memberikan bimbingan seefisien mungkin. ${ }^{7}$

\section{METODE PENULISAN}

Penulis menggunakan metode kuantitative untuk menemukan jawaban

\footnotetext{
${ }^{6}$ Wursanto. Dasar-Dasar Ilmu Organisasi, 199.

${ }^{7}$ Imron Widjaja, Bobby Kurnia Putrawan, Hengki Wijaya. "Manajemen Pendidikan Agama Kristen Melalui Pelayanan Penggembalaan Dalam Kelompok Sel." EDUKASI: Jurnal Penelitian Pendidikan Agama Dan Keagamaan 18, No.2 (2020): 159-170. Https://Doi.Org/10.32729/Edukasi.V18i2.689.
} 
atas rumusan masalah: Apakah Implementasi kepemimpinan yang berhasil berdasarkan kitab Nehemia bagi kalangan hamba Tuhan di GKKI se Jawa Tengah? Apakah Karakter mengandalkan Tuhan adalah karakter yang paling dominan diteladani kalangan hamba Tuhan di GKKI se Jawa Tengah? Kategori latar belakang manakah yang paling dominan menentukan implementasi kepemimpinan hamba Tuhan yang berhasil berdasarkan kitab Nehemia bagi kalangan hamba Tuhan di GKKI se Jawa Tengah?

\section{HASIL PEMBAHASAN}

Nehemia seorang yang tekun berdoa. Bagi Nehemia, doa merupakan bagian hidup dan kerja sehari-hari. Doa adalah reaksinya yang pertama ketika ia mendengar kesulitan para emigran di Yerusalem. Nehemia juga bukan seorang yang asing di takhta kasih karunia (Nehemia 1:4, 6; 2:4, 9; 5:19; 6:14, 22, $29)^{8}$.

Seorang pemimpin Kristen yang efektif haruslah seorang yang sudah dilahirkan baru di dalam Kristus, yang bersih dalam moral, dan menjaga standar kebenaran menurut Tuhan. ${ }^{9}$ Kristus datang ke dunia untuk membawa manusia dari

\footnotetext{
${ }^{8}$ J. Oswald Sanders, Kepemimpinan Rohani. (Batam Centre: Gospel Press, 2002), 280

${ }^{9}$ George Barna, Leaders On Leadership. (Malang: Gandum Mas, 2002), 103
}

kegelapan menuju terang. Kegelapan telah melingkupi watak dan karakter manusia karena Iblis senantiasa berusaha merusak moralitas manusia. Tidak mengherankan bahwa sudah terlampau banyak pemimpin Kristen dan non-Kristen abad sekarang, yang ternyata sudah menyakiti hati rakyatnya dengan tidak memedulikan keadilan dan kesejahteraan.

Salah satu sifat penting kepemimpinan Kristen yang efektif ialah kemampuan untuk menyesuaikan bentuk kepribadian seseorang dengan situasi tertentu ${ }^{10}$. Karakter dan moral yang sudah mulai rusak harus dipulihkan kembali melalui pendamaian oleh Tuhan Yesus, supaya bersih dan dilayakkan untuk menjadi seorang pemimpin umat manusia. Nehemia adalah seorang pendoa karena dia sudah lahir baru. Kebijaksanaan dan hikmat bersumber dari Allah. Sesungguhnya, agar seseorang dapat memimpin atau memberi pengaruh secara rohani kepada orang lain, ia harus memperdalam hubungannya dengan Tuhan. $^{11}$

Komunikasi yang dijalin terusmenerus dengan Allah merupakan hubungan yang bersifat supernatural, yang dapat menghasilkan perubahan kepada

${ }^{10}$ Kenneth O. Gangel, Membina Pemimpin Pendidikan Kristen. (Malang: Gandum Mas, 1998), 104

${ }^{11}$ Stacy T. Rinehart, Paradoks Kepemimpinan Pelayan (Jakarta: Immanuel, 2003) 114 
para pemimpin dalam mengambil keputusan yang bijaksana. Kalau seorang pemimpin putus hubungan dengan Allah dan orang-orangnya, ia kehilangan sifat rela diajarnya ${ }^{12}$.

Orang Kristen yang bijaksana adalah orang yang memiliki pandangan yang tepat mengenai anugerah Tuhan. Paulus menekankan hal ini ketika dia menulis kepada Titus: "Karena kasih karunia Allah yang menyelamatkan semua manusia sudah nyata. Ia mendidik kita untuk meninggalkan kefasikan dan keinginan-keinginan duniawi dan supaya kita hidup bijaksana, adil dan beribadah di dalam dunia sekarang ini." (Titus 2:1112).

Nehemia memiliki sesuatu yang khas di dalam dirinya ${ }^{13}$. Ia seorang yang peduli kepada orang lain. Tampak jelas, ia memerhatikan kesejahteraan orang lain secara tulus, dan para musuhnya pun mengetahui hal itu (Nehemia. 2:10). Ia mengekspresikan perhatiannya dengan berpuasa, berdoa, dan menangis (Nehemia. 1:4-6). Ia menempatkan dirinya bersama dengan bangsanya yang menderita karena dosa-dosa mereka (Nehemia. 1:6).

Panggilan tertinggi bagi para pemimpin sekarang ialah panggilan untuk

\footnotetext{
12 John C. Maxwell, 21 Menit Paling Bermakna Dalam Hari-Hari Pemimpin Sejati. (Batam Centre: Interaksara, 2002), 123

${ }^{13}$ J. Oswald Sanders, Kepemimpinan Rohani, 280.
}

saling mengasihi dengan tulus hati, sebagaimana kita telah saling mengasihi dan mengampuni. Iman membangun iman. Pesimisme berubah menjadi iman ${ }^{14}$. Tugas utama kepemimpinan rohani adalah pembangunan iman orang lain. Kita sering sulit mendengarkan Roh Kudus membisikkan panggilan ini ke dalam hati kita bila kita telah terlatih lebih mendukung sistem-sistem yang membenarkan dirinya sendiri alih-alih yang lain ${ }^{15}$.

Nehemia adalah seorang yang berpandangan jauh ke depan. Ia mengetahui bahwa pasti akan bangkit perlawanan, jadi ia meminta sang raja memberikan mandat tertulis agar perjalanannya aman dan ia mendapat dukungan untuk menyelesaikan mandat tersebut, "... memasang balok-balok pada pintu-pintu gerbang di benteng bait suci, untuk tembok kota ..." (Nehemia. 2:8) Ia merencanakan strateginya dengan cermat. Tuhan memakai seorang biasa yang awam, yang memiliki tujuan dan visi yang tidak biasa. ${ }^{16}$ Nehemia mengungkapkan visinya dengan istilah yang sesederhana mungkin. Sasaran bangsa itu adalah pembangunan kembali tembok Yerusalem ${ }^{17}$.

\footnotetext{
${ }^{14}$ J. Oswald Sanders, Kepemimpinan Rohani, 282.

${ }^{15}$ George Barna, Leaders On Leadership, 9495.

${ }^{16}$ Meyer, Kepemimpinan Kristen, 353.

17 John C. Maxwell, 21 Menit Paling

Bermakna Dalam Hari-Hari Pemimpin Sejati, 84.
} 
Setiap calon pemimpin harus memunyai visi. Tanpa visi, ia tidak mungkin bisa mencapai tujuan. Visi yang jelas akan memungkinkan seorang pemimpin percaya dan yakin. Visi berkaitan dengan penciptaan sesuatu yang baru, tidak mengabaikan yang lampau, tetapi membangun di atas fondasi sebelumnya dan yang akan muncul sebagai realitas yang lebih baik dibanding realitas sekarang. ${ }^{18}$

\section{Visi kepemimpinan adalah} kemampuan pemimpin untuk melihat dan memahami keinginan suci yang ditulis oleh Allah di dalam batinnya bagi organisasi serta kepemimpinannya. Di dalam visi itu, terdapat kehendak Allah yang khusus bagi kepemimpinan seorang pemimpin. $^{19}$

Nehemia sementara membangun tembok Yerusalem yang sudah hancur. Para musuh berdatangan terus menerus menyerang Nehemia dalam segala kesempatan. Teror melalui omongan maupun ancaman fisik membuat Nehemia mengatur strategi agar para pembangun tembok Yerusalem membangun tembok

\footnotetext{
${ }^{18}$ Natanael Winanto, Antonius Missa, dan Juan Ananta Tan. "Surat-Surat Pastoral Sebagai Petunjuk Praktis Penggembalaan Untuk Jemaat (Pastoral Letters As A Shepharding Practical Guidelines In Congregation)". QUAERENS: Journal of Theology and Christianity Studies 2, no.1 (2020): 44-61. https://doi.org/10.46362/quaerens.v2i1.14.

${ }^{19}$ Yacob Tomatala, Anda Juga Bisa Menjadi Pemimpin Visioner. (Jakarta : YT Leadership Foundation, 2005), 24.
}

sambil mengangkat pedang. Komitem Nehemia sangat tinggi sehingga membuat dirinya mengarahkan pandangan kepada Tuhan. Maedjaja kembali memberikan penjelasan bahwa

Suatu kebiasaan mengarahkan mata rohani kita kepada Tuhan, karena akan tiba waktunya, kita dibimbing kepada ke dalam suatu kehidupan rohani yang mempunyai pengertian dimensi yang baru. semua pemimpin Kristen akan menemukan dan mengalami suatu keadaan, dimana pikiran, jiwa dan roh mereka sungguh-sungguh dipenuhi dengan damai sejahtera. ${ }^{20}$

Nehemia memiliki pandangan yang jauh ke depan. Ia tahu bahwa perlawanan pasti akan bangkit, jadi ia meminta suratsurat dari raja agar perjalanannya aman dan ia mendapat sumber-sumber untuk menyelesaikan tugas itu, "Memasang balok-balok pada pintu-pintu gerbang di benteng bait suci, untuk tembok kota" (Nehemia. 2:8). Ia dengan cermat merencanakan strateginya. Tuhan memakai orang biasa, yang awam yang memiliki tujuan-tujuan dan visi-visi yang tidak biasa. Nehemia mengungkapkan visinya dengan istilah yang sederhana mungkin. Sasaran bangsa itu adalah membangun kembali tembok Yerusalem.

Nehemia memiliki sasaran dalam kepemimpinannya. Sasaran Nehemia adalah untuk membangun kembali tembok

\footnotetext{
${ }^{20}$ Yacob Tomatala, Anda Juga Bisa Menjadi
} Pemimpin Visioner, 178. 
Yerusalem yang telah runtuh dan terbakar (Nehemia. 1:3; Nehemia. 2:17). Nehemia mengajak penduduk dan mereka mendukungnya. Hariono Soemarsono mengatakan, "Setiap usaha layaknya mempunyai suatu visi usaha, misi usaha, sasaran secara kualitatif dan target usaha secara kuantitatif."21 Salah satu tugas fundamental dari kepemimpinan adalah memastikan bahwa suatu organisasi memiliki visi yang sama akan masa depannya.

Doa yang Nehemia ucapkan (Nehemia. 1:9,10), sesungguhnya mengacu pada janji Tuhan yang ditulis dalam kitab Ulangan. Spiritualitas seseorang salah satunya dapat dilihat dari kehidupan doanya. Orang yang senantiasa menaruhkan setiap pergumulan hidupnya ke dalam tangan Tuhan melalui doadoanya dapatlah dikatakan orang tersebut memiliki kehidupan spiritualitas tinggi. Tentu saja setelah berdoa, orang tidak diperkenankan melakukan tindakan atau perbuatan yang tidak berkenan di hadapan manusia terlebih lagi Tuhan.

Salah satunya reaksi pertama yang dikerjakan Nehemia adalah berdoa. "Doa adalah reaksi pertamanya begitu mendengar kesulitan para emigran di Yerusalem. Nehemia juga bukan orang

\footnotetext{
${ }^{21}$ Hariono Soemarsono. Tim Dan Teamwork Plus. (Bandung: Lembaga Literatur Baptis, 2003), 37.
}

asing di takhta kasih karunia (Nehemia. $1: 4,6 ; 2: 4,9 ; 5: 19 ; 6: 14,22,29) .{ }^{22}$ Reaksi yang Nehemia diperlihatkan merupakan reaksi terhadap penderitaan yang dihadapi umat Israel dan reaksi terhadap keadaan Yerusalem yang tinggal puing-puing. Nehemia 1:4 mengatakan, "Ketika kudengar berita ini, duduklah aku menangis dan berkabung selama beberapa hari. Aku berpuasa dan berdoa ke hadirat Allah semesta langit."

Ini artinya ada sebuah keprihatinan yang sedang Nehemia tunjukkan kepada kaum sebangsanya, keprihatinan akan keterpurukan hidup bangsa Yahudi. "Nehemia berupaya untuk mendapatkan kemurahan Raja, melalui permohonan kepada Tuhan agar kasih karunia Tuhan dilimpahkan dalam hidup Nehemia."23 Seorang pemimpin yang bijaksana adalah orang yang suka berdoa. Seorang pemimpin yang bijaksana akan berlutut dalam penyembahan yang penuh doa dan kerendahan hati lalu naik ke suatu

\footnotetext{
${ }^{22}$ Patricia Diana Hasibuan dan Susanti Embong Bulan. "Kepemimpinan Dalam Gereja Katolik Paroki Ignatius Loyola Dan Huria Kristen Batak Protestan Setiabudi Menuju Persatuan (Leadership In The Ignatius Loyola Parish Catholic Church And Setiabudi Batak Christian Protestant Church To Unity)." QUAERENS: Journal of Theology and Christianity Studies 1, no.2 (2019): 111-121. https://doi.org/10.46362/quaerens.v1i2.5.

${ }^{23}$ Patricia Diana Hasibuan dan Susanti Embong Bulan. "Kepemimpinan Dalam Gereja Katolik Paroki Ignatius Loyola Dan Huria Kristen Batak Protestan Setiabudi Menuju Persatuan (Leadership In The Ignatius Loyola Parish Catholic Church And Setiabudi Batak Christian Protestant Church To Unity): 2.
} 
tingkatan yang baru dalam hal hidup kudus dan benar.

Selain itu adanya kesadaran dari Nehemia atas segala kekurangan dan kelemahan Nehemia di hadapan Tuhan Allah, dapat dijadikan sebuah penggambaran bahwa Nehemia seorang yang memiliki spiritualitas tinggi. Orang yang memiliki spiritualitas tinggi terlihat dari sikap hidupnya yang mengakui Tuhan Allah diatas segala-segalanya. Sebab sebagai manusia, yang memiliki kekuatan dan kelebihan seperti apapun, manusia tetap tidak dapat melebih Tuhan Allah. Manusia hidupnya dikuasai oleh doa yang dapat menjadikan hidupnya jauh dari Tuhan Allah. Karena itu, Nehemia mohon ampunan pada Tuhan, Nehemia berdoa mewakili dirinya, keluarganya, yaitu keluarga Daud dan bangsa Israel seluruhnya. Doa inilah yang Nehemia panjatkan.

Sebagai seorang pemimpin Nehemia memandang kehidupan rohani adalah dasar dari keberhasilan dalam kepemimpinannya. Setiap calon pemimpin harus punya visi. Tanpa visi tidak mungkin dia bisa mencapai apa yang dituju. Kejelasan visi akan memungkinkan seorang pemimpin menjadi percaya dan yakin. Visi berkaitan dengan menciptakan sesuatu yang baru, tidak meremehkan yang lampau, tetapi membangun di atas fondasi yang dulu dan yang sekarang, muncul dengan realitas yang lebih baik, daripada realitas yang ada sekarang.

Dari visi pemimpin itu dapat dilihat bahwa seorang pemimpin memiliki kehidupan rohani yang mapan. Sebab visi didapatkan dari pergumulan secara pribadi dengan Tuhan Allah, sehingga Tuhan Allah memberikan sebuah visi atau sasaran untuk dicapai oleh seorang pemimpin.

Nehemia senantiasa mengutamakan Tuhan di atas segalanya, sehingga Tuhanlah yang menjadi nomor satu dalam hidupnya. Nehemia memiliki rasa takut akan Tuhan diperlihatkan dari tindakan Nehemia yang senantiasa berpegang pada perjanjian dan kasih setia Tuhan. Kata "Berpegang" dalam bahasa Ibrani menggunakan kata "rm'v;" (Shawmar) diartikan "Menjaga."24 Kata "rm'v;" (Shawmar) memiliki makna kata "Mengindahkan setiap perkataan Tuhan artinya orang yang senantiasa melakukan perintah dan menjauhi larangan Tuhan.,"25

Nehemia memiliki sasaran dalam kepemimpinannya. Sasaran Nehemia adalah untuk membangun kembali tembok Yerusalem yang telah runtuh dan terbakar (Neh. 1:3; Neh. 2:17). Nehemia mengajak penduduk dan mereka mendukungnya. Hariono Soemarsono mengatakan, "Setiap

\footnotetext{
24 "Shawmar," Strong Hebrew Greek Dictionaries. "CD-ROM," E-Swords - Indonesian Version., 2008.

25 "Shawmar," Strong Hebrew Greek Dictionaries.
} 
usaha layaknya mempunyai suatu visi usaha, misi usaha,sasaran secara kualitatif dan target usaha secara kuantitatif."26 Salah satu tugas fundamental dari kepemimpinan adalah memastikan bahwa suatu organisasi memiliki visi yang sama akan masa depannya.

Nehemia sadar, Tuhan seperti apa yang kepada-Nya mengajukan seluruh doa permohonan, "Ya, TUHAN, Allah semesta langit, Allah yang maha besar dan dahsyat, yang berpegang pada perjanjian dan kasih setia-Nya terhadap orang yang kasih kepada-Nya dan tetap mengikuti perintahperintah-Nya. Karena itu, Nehemia mohon ampunan pada Tuhan, Nehemia berdoa mewakili dirinya, keluarganya, yaitu keluarga Daud dan bangsa Israel seluruhnya.

Kata "Doa" dalam bahasa Ibrani menggunakan kata "ll'P;" (Palal) secara literal diartikan “Doa.” Kata "ll'P;" (Palal) memiliki makna "permohonan bantuan."27 Doa yang Nehemia ucapkan (Nehemia. $1: 9,10)$, sesungguhnya mengacu pada janji Tuhan yang ditulis dalam kitab Ulangan. Nehemia memohon supaya orang Israel mengalami kebangunan rohani dan nama Tuhan dipermuliakan kembali. Hal inilah yang menjadi inti dari doa Nehemia, yakni

\footnotetext{
${ }^{26}$ Hariono Soemarsono, Tim Dan Teamwork Plus. (Bandung: Lembaga Literatur Baptis, 2003), 37.

27 "Palal," Strong Hebrew Greek

Dictionaries. "CD-ROM," E-Swords - Indonesian Version., 2008.
}

terjadinya restorasi rohani bagi bagsa Israel dan untuk hal ini Nehemia siap diutus Tuhan.

Penyesalan akan dosa atau kesalahan dapat dijadikan sebagai momentum indah bagi seorang pemimpin mengintropeksi diri atas kehidupannya secara pribadi. Nehemia mengaku segala dosa yang telah dilakukan oleh bangsa Israel. Kata "Mengaku segala dosa" dalam bahasa Ibrani menggunakan kata "'דירד", (Yadad) diartikan "Mengaku."28 Kata “יִירד" (Yadad) memiliki makna "Menangisi, melempar dengan tangan."29 Artinya Nehemia menangisi perbuatan bangsa Israel yang begitu jijik di hadapan Allah, dan perbuatan yang jijik ini Nehemia lemparkan jauh dari kehidupannya dan kehidupan bangsa Israel.

Nehemia 1:6-7 mengatakan,

Berilah telinga-Mu dan bukalah mata$\mathrm{Mu}$ dan dengarkanlah doa hamba-Mu yang sekarang kupanjatkan ke hadiratMu siang dan malam bagi orang Israel, hamba-hamba-Mu itu, dengan mengaku segala dosa yang kami orang Israel telah lakukan terhadapMu. Juga aku dan kaum keluargaku telah berbuat dosa. Kami telah sangat bersalah terhadap-Mu dan tidak mengikuti perintah-perintah, ketetapan-ketetapan dan peraturan-

\footnotetext{
28 "Yadad," Strong Hebrew Greek

Dictionaries. "CD-ROM," E-Swords - Indonesian Version., 2008

29 "Yadad," Strong Hebrew Greek

Dictionaries.
} 
peraturan yang telah Kauperintahkan kepada Musa, hamba-Mu itu.

Ini merupakan doa Nehemia yang menyadari bahwa dosa adalah penghalang datang berkat dari Tuhan Allah. Dosa yang dilakukan oleh bangsa Yahudi adalah dosa penyembahan berhala sehingga Tuhan menyerahkan bangsa Yahudi kepada bangsa Babil. Nehemia menyadari perannya sebagai bagian dari orang-orang yang berdosa, Ia menyadari perannya sebagai orang yang diberi janji dan perintah oleh Tuhan. Ia menjadi orang yang berdoa untuk suksesnya apa yang diharapkannya bagi bangsanya dan bukan untuk diri sendiri saja. Artinya dosa merupakan penghalang dari keberhasilan seseorang untuk itu dosa harus dikalahkan sehingga Tuhan berkarya dalam hidup orang percaya. Nehemia memiliki sebuah keyakinan kokoh bahwa penyelesaian dosanya beserta umat Israel merupakan kunci keberhasilannya di dalam setiap langkah hidupnya.

Dalam sebuah kepemimpinan intelektual serta kemampuan atau skill individual pemimpinan sangat berperan besar. Namun sepintar apapun pemimpin itu apabila tidak memiliki kerendahan hati maka sia-sialah kepandaian pemimpin itu. Sebab untuk menjadi yang terbesar di antara orang percaya seorang pemimpin rohani harus bersedia menjadi hamba bagi orang percaya. Artinya seorang pemimpin harus melayani kehidupan orang yang dipimpinnya.

Nehemia 1:10 mengatakan, "Bukankah mereka ini hamba-hamba-Mu dan umat-Mu yang telah Kaubebaskan dengan kekuatan-Mu yang besar dan dengan tangan-Mu yang kuat ?" Kata "Kaubebaskan" berasal dari kata "hd;P;" (Padah) diartikan "melepaskan dan memelihara."30 Nehemia mengakui segala kekuatan, kekayaan dan keberhasilan Nehemia dan bangsa Israel bukanlah dari kekuatan manusia melainkan dari Tuhanlah keberhasilan tersebut.

Salah satu syarat seorang pemimpin adalah mengandalkan Tuhan dalam segala perkara yang dihadapinya. Untuk dapat mengandalkan Tuhan, seorang pemimpin harus mencari kehendak Tuhan terlebih dahulu. Sikap mengandalkan Tuhan merupakan bentuk kerendahan hati dan kepenundukkan diri seorang pemimpin Kristen. Bahkan pemimpin Kristen haruslah seorang pribadi yang senantiasa menaruh iman dan pengharapannya kepada Tuhan.

Susabda mengatakan,

Bukankah iman itu bersandar pada Allah yang hidup, yang menjanjikan untuk memberikan pertolongan pada saatnya (Matius. 10:19) dan bukan bersandar pada

\footnotetext{
30 "Padah," Strong Hebrew Greek

Dictionaries. "CD-ROM," E-Swords - Indonesian Version., 2008.
} 
keyakinan dan perasaan pribadi? ... Setiap orang yang hanya bersandar pada akal dan perasaanya, tidak mengenal hal-hal yang baik yang betul-betul dibutuhkannya (Amsal 3:1-7) permintaan mereka terjerat oleh nafsu (Yakobus 4:3). ${ }^{31}$

Iman kepada Tuhan sebagai dasar kokoh yang dapat menopang setiap umatNya untuk menjadi pemenang. Ketika perasaan kekuatiran, kebimbangan mulai mengintimidasi jalan seorang pemimpin maka haruslah mampu mengalahkan perasaan itu dan berusaha untuk menyerahkan kepada Tuhan dan bersyukur kepadanya. Kebergantungan kepada Allah akan membawa kepada suatu kemenangan dan keberhasilan dalam kepemimpinan.

Nehemia 1:11 mengatakan, "Ya, Tuhan, berilah telinga kepada doa hamba$\mathrm{Mu}$ ini dan kepada doa hamba-hamba-Mu yang rela takut akan nama-Mu, dan biarlah hamba-Mu berhasil hari ini dan mendapat belas kasihan dari orang ini." Ketika itu aku ini juru minuman raja." Nehemia mengakui bahwa dirinya adalah Hamba Tuhan Allah, yang berarti segala apa yang dilakukan Nehemia berasal dari perintah Tuhan Allah. Jadi dimengerti bahwa Tuhan telah memilih Nehemia untuk menjadi pelayan-Nya. Pemilihan Nehemia oleh Tuhan ditandai dengan adanya otoritas dalam hidup Nehemia.

\footnotetext{
${ }^{31}$ Susabda, Lo.Cit., 204.
}

Kemampuan Nehemia untuk menggerakkan semua lapisan umat Israel yang telah kembali ke Yerusalem bukan hanya sikap nasionalisme Israel yang tinggi. Tetapi adanya faktor internal dalam diri Nehemia, yang mana Nehemia memiliki kemampuan mengoordinasi dan kemampuan berstrategi sehingga banyak orang mampu berada di bawah pimpinan Nehemia.

Dalam Nehemia 2:1 firman Tuhan mengatakan,

Pada bulan Nisan tahun kedua
puluh pemerintahan raja Artahsasta, ketika menjadi tugasku untuk menyediakan anggur, aku mengangkat anggur dan menyampaikannya kepada raja. Karena aku kelihatan sedih, yang memang belum pernah terjadi di hadapan raja.

Kata "Pada bulan" dalam bahasa Ibrani "אֶרְיֶה" ("eyeh) secara literal diartikan "Itu adalah",32 Maksudnya adalah "Itu adalah bulan Nisan." Akan tetapi apabila dilihat dari bentuk makna katanya maka kata "אהִיֶיה" ("eyeh) memiliki arti "Jadilah, terpenuhi; artinya satu bulan yang dinantikan telah berlalu kini menjadi bulan baru yakni bulan Nisan." Bulan Nisan merupakan bulan pertama dalam kalender umat Israel, yang seringkali disebut dengan sebutan bulan Abib.

32 "Heyeh," Strong Hebrew Greek

Dictionaries. "CD-ROM," E-Swords - Indonesian Version., 2008. 
Perhitungan kalender Yahudi diawali pada saat Yahudi keluar dari Mesir terjadi pada bulan Nisan (Abib), dan juga pada peristiwa penyeberangan sungai Yordan di bawah komanda Yosua.

Artinya bulan ini memiliki implikasi rohani dalam kehidupan umat Israel, yang mana umat Israel mengakui bahwa bulan Nisan merupakan bulan kemenangan bagi Umat Israel. ${ }^{33}$ Dengan kata lain bahwa Nehemia memiliki sebuah strategi hebat yang diwarisinya dari para bapa-bapa leluhur, dimana para bapa leluhur melakukan pembebasan bagi bangsa Yahudi di saat bulan Nisan.

Dapatlah dimengerti bahwa Nehemia mengerti dengan jelas kapan waktunya harus bertindak. Nehemia bertindak pada saat bulan Nisan. Artinya sebelum Nehemia mengatakan maksud hatinya dihadapan raja, Nehemia mengatur segala sesuatu dengan baik yang menyangkut tingkah laku dan tutur katanya untuk disampaikan di hadapan raja. Persiapan matang telah Nehemia persiapkan agar ketika raja bertanya, Nehemia tidak memberikan jawaban yang salah.

\section{Implementasi Kepemimpinan Menurut}

Kitab Nehemia Bagi Kalangan Hamba

Tuhan di GKKI se-Jawa Tengah

Kelemahlembutan

seorang

pemimpin merupakan modal utama

pemimpin untuk mengarahkan dan mengayomi orang-orang yang dipimpinnya. Seorang pemimpin mengepalai banyak orang dengan latar belakang yang berbeda-beda, baik dari segi intelektualnya, ekonomi, kesukaan, emx osi dan sebagainya. Perbedaan yang ada pada diri seorang bawahan menuntut tanggapan yang berbeda pula dari seorang pimpinan dan seorang pemimpin tidak boleh memperlakukan bawahan satu dengan lainnya dengan kondisi yang sama. Thomas Makadi mengatakan bahwa "Lemah lembut itu menunjukkan sikap batin. Orang yang lemah lembut tidak mendendam terhadap tindakan yang kasar, tidak tawar hati dalam kemalangan, karena segala sesuatu diterimanya sebagai jalan Allah bagi dia dalam tujuan Allah yang penuh. hikmat dan kasih (patuh pada kehendak Allah)." ${ }^{34}$ Untuk itu seorang pemimpin harus memiliki kelemah lembutan untuk dapat membimbing seorang bawahan dengan karakter yang berbeda-beda. Selain kelemahlembutan seorang pemimpin dituntut untuk memiliki kerendahan hati, dengan sikap kerendahan

\footnotetext{
${ }^{34}$ Makadi, Lo.Cit., 34.
} 
hati maka seorang pemimpin dapat diterima oleh semua bawahannya. Sikap kerendahan hati seorang pemimpin salah satunya dapat ditunjukkan dengan seorang pemimpin yang meninggalkan keteladanan hidup bagi bawahan.

Seorang pemimpin harus memiliki sikap hidup tunduk dan bergantung sepenuh pada Tuhan Allah. Seorang pemimpin akan banyak menghadapi masalah dan pergumulan dalam hidup sehari-hari. Bukan hanya masalah secara pribadi, melainkan juga masalah pribadi bawahan serta masalah organisasi yang dipimpinnya. Jikalau seorang pemimpin tidak hidup tunduk dan bergantung kepada Tuhan Allah maka pemimpin tidak akan mampu mengatasi dan menyelesaikan masalah yang dihadapinya.

Secara sekuler yang dinamakan pimpinan adalah orang yang berada diatas setiap bawahan. Melainkan dalam dunia kepemimpinan Kristen, pemimpin adalah seorang hamba yang melayani bawahannya. Untuk dapat melayani bawahan dengan berbeda latar belakang dan karakter maka seorang pemimpin harus memiliki kerendahan hati. Dengan kerendahan hati maka fungsi seorang pemimpin sebagai pelayanan akan berjalan sebagaimana yang diharapkan. Selain kerendahan hati maka seorang pemimpin harus peduli terhadap bawahan. Sikap peduli terhadap bawahan ini tidak boleh dilakukan dengan membeda-bedakan bawahan satu dengan lainnya. Dalam pikiran seorang pemimpin semua bawahan sama dan harus dilindungi.

Syarat yang terpenting untuk menjadi seorang pemimpin Kristen ialah seorang yang memiliki hikmat. Sifat bijaksana ini menggambarkan seseorang yang dapat dipercaya dan dapat memberikan pertimbangan yang tepat, tidak plin-plan. Untuk mendapatkan kehidupan yang dipenuhi dengan hikmat Tuhan, seseorang pemimpin harus hidup mengandalkan Tuhan. Pemimpin menghadapi dan mengatur banyak bawahan untuk diarahkan pada sebuah sasaran dari kelompok yan dipimpinnya. Untuk mengatur banyak bawahan, seorang pemimpin harus memiliki hikmat dan penuh dengan pertimbangan. Dengan adanya hikmat dan penuh pertimbangan, nantinya keputusan yang diputuskan tidak merugikan seorang bawahan. Salah satu unsur penting pengorganisasian adalah kesanggupan untuk bergaul dengan orang secara benar-benar ramah, sopan, tetapi mantap. Nehemia seorang pemimpin yang tidak melakukan pekerjaan dengan serampangan. Nehemia mengorganisasikan orang-orangnya menurut keluarga dan menurut prioritas yang telah direncanakannya, mulai dari gerbang kota tersebut. 
Tembok Yerusalem berhasil dibangun kembali karena kemampuan Nehemia untuk bekerja sama dengan orang lain dan memimpin mereka ke mana mereka harus menuju. Dia berupaya melibatkan sebanyak mungkin orang dalam prosesnya dan bergerak maju dengan mereka yang sudah siap. Dia mengorganisasi mereka dalam kelompokkelompok alami berdasarkan hubungan.

Dalam membuat sebuah keputusan yang berkenaan dengan organisasi atau sekelompok orang yang dipimpinnya, maka seorang pemimpin harus banyak mendengar sehingga banyak sekali pertimbangan yang didapatkan. Seorang pemimpin yang membuat keputusan yang tidak efektif pada dasarnya mengandung dua masalah: keragu-raguan untuk membuat keputusan, dan membuat keputusan yang tidak tepat. Satu keputusan yang salah dapat membawa pemimpin ke jalan buntu atau ke jalan yang menuju kehancuran. Sebagai seorang pemimpin soal mengambil keputusan itu merupakan seni yang harus dikuasai.

Strategi dalam kepimpinan adalah syarat mutlak dan seorang pemimpin yang handal memiliki strategi jitu untuk dapat mengembangkan organisasi serta orang yang dipimpinnya. Bukan mata yang memerintah maupun mata yang memberi teror rasa takut untuk menundukkan orang. Nehemia 2: 11-20 mengisahkan bagaimana reaksi Nehemia ketika melihat bahwa kondisi kota Yerusalem yang porak poranda, ia tidak ambil pusing. Ia langsung memutuskan untuk beraksi (band. ayat 17) dikatakan: Berkatalah aku (Nehemia) kepada mereka, "Kamu lihat kemalangan yang kita alami, yakni Yerusalem telah menjadi reruntuhan dan pintu-pintu gerbangnya telah terbakar. Mari, kita bangun kembali tembok Yerusalem, supaya kita tidak lagi dicela."

Di Yerusalem saat itu meski dalam kondisi terjajah, masih ada tua-tua dan pemimpin Israel. Tetapi mereka tidak melakukan apa-apa terhadap tembok Yerusalem yang runtuh. Maka itu Nehemia berkata: “...Lihat... ”Ia ingin agar semua pemimpin mau membuka matanya dan melihat kondisi sekitarnya bahkan melihat kondisi dirinya sendiri.

Tabel Hasil Analisa Data Exogenous Variables Secara BersamaSama Terhadap Endogenous Variable Dengan Variabel Moderat Hamba Tuhan di GKKI Se Jawa Tengah

\begin{tabular}{|c|l|c|c|}
\hline No & Variabel moderat & $\mathrm{F}$ & $\mathrm{Sig}$ \\
\hline 1. & Jenis Kelamin & 11,75 & 0,001 \\
\hline 2. & Umur Responden & 4,393 & 0,004 \\
\hline 3. & $\begin{array}{l}\text { Jabatan } \\
\text { Kependetaan }\end{array}$ & 0,941 & 0,397 \\
\hline 4. & Lamanya Melayani & 2,215 & 0,098 \\
\hline 5. & $\begin{array}{l}\text { Pendidikan } \\
\text { Teologi Formal }\end{array}$ & 5,041 & 0,004 \\
\hline 6. & $\begin{array}{l}\text { Pendidikan } \\
\text { Teologi Informal }\end{array}$ & 2,543 & 0,052 \\
\hline
\end{tabular}


Gambar Urutan Exogenous Variables

Secara Bersama-Sama Terhadap

Endogenous Variable Dengan Variabel

Moderat Hamba Tuhan di GKKI Se Jawa

Tengah

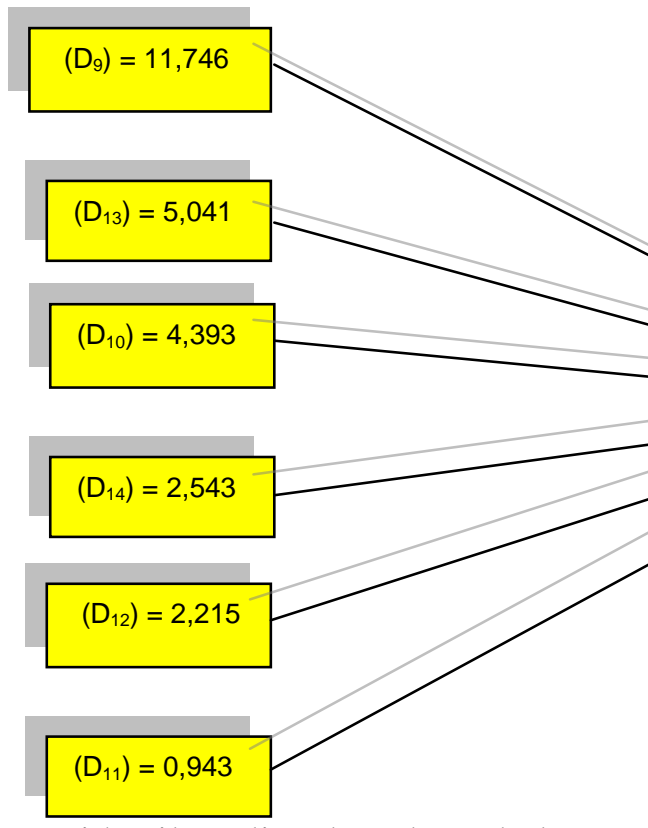

Dari hasil analisa data dan tabel

diatas maka dapat disimpulkan bahwa

lamanya melayani hamba Tuhan GKKI se

Jawa Tengah bukanlah variable moderat

yang paling dominan berpengaruh

terhadap Exogenous Variables Secara

Bersama-Sama Terhadap Endogenous

Variable. Variabel yang paling

berpengaruh dalam implementasi

kepemimpinan hamba Tuhan yang berhasil

berdasarkan kitab Nehemiah di kalangan

hamba Tuhan di GKKI se Jawa Tengah

adalah latar belakang jenis kelamin.

Classification and Regression Tree

(CRT) berfungsi untuk membuat diagram

klasifikasi dan keputusan untuk

mengidentifikasikan kelompok dan

memprediksi perilaku. Pendekatan analisis ditetapkan dengan Classification and

Regression Tree (CRT) antara Exogenous

Variables Secara Bersama-Sama Terhadap

Endogenous Variable, dengan hasilnya seperti gambar berikut ini:
Endogenous

Variable (Y) dan

Exogenous

Variables (X)

Hasil analisis Classification and Regression Tree (CRT) menunjukkan bahwa latar belakang pendidikan hamba Tuhan di GKKI se Jawa Tengah ( $\left.\mathrm{D}_{9}\right)$

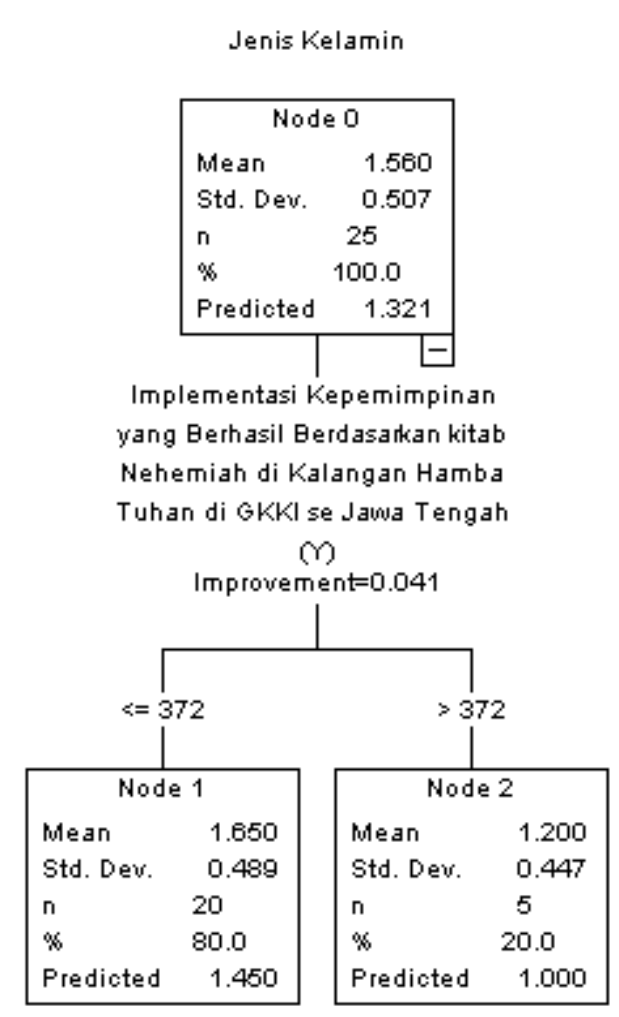


merupakan kategori latar belakang hamba Tuhan GKKI se Jawa Tengah yang paling dominan dalam implementasi kepemimpinan hamba Tuhan yang berhasil berdasarkan kitab Nehemiah. Berdasarkan hasil uji hipotesis di atas, maka hipotesis ketiga yang berbunyi "kategori latar belakang pendidikan hamba Tuhan dominan menentukan implementasi kepemimpinan hamba Tuhan yang berhasil berdasarkan kitab Nehemiah bagi kalangan hamba Tuhan di GKKI se Jawa Tengah" dalam penelitian terbukti kebenarannya.

$$
\text { Dalam implementasi }
$$

Kepemimpinan yang Berhasil Berdasarkan kitab Nehemiah di Kalangan Hamba Tuhan di GKKI se Jawa Tengah, penulis membuat tabel implikasi sebagai berikut:

\begin{tabular}{|l|l|c|}
\hline \multicolumn{1}{|c|}{ Temuan } & Implikasi & $\begin{array}{c}\text { Tindakan } \\
\text { Lanjut }\end{array}$ \\
\hline Hipotesa & Perlu & 1. \\
Pertama : & peningkat & Mengad \\
Implementasi & akan \\
kepemimpinan & kan & seminar \\
yang berhasil & implement & kepemi \\
berdasarkan & asi & mpinan \\
kitab Nehemiah & kepemimp & bagi \\
bagi kalangan & inan yang & kalanga \\
hamba Tuhan di & berhasil & n \\
GKKI se Jawa & bagi & hamba \\
Tengah dalam & kalangan & Tuhan \\
kategori cukup, & hamba & di \\
dalam penelitian & Tuhan di & \\
\hline
\end{tabular}

\begin{tabular}{|c|c|c|}
\hline ini terbukti. & $\begin{array}{l}\text { GKKI se } \\
\text { Jawa } \\
\text { Tengah }\end{array}$ & $\begin{array}{l}\text { GKKI } \\
\text { se Jawa } \\
\text { Tengah }\end{array}$ \\
\hline $\begin{array}{l}\text { Hipotesa Kedua: } \\
\text { Dimensi } \\
\text { Mengandalkan } \\
\text { Tuhan sebagai } \\
\text { karakter } \\
\text { Nehemiah yang } \\
\text { Paling dominan } \\
\text { diteladani } \\
\text { kalangan hamba } \\
\text { Tuhan di GKKI } \\
\text { se Jawa Tengah } \\
\text { dalam } \\
\text { Mengimplement } \\
\text { asikan } \\
\text { kepemimpinan } \\
\text { yang berhasil } \\
\text { berdasarkan } \\
\text { Kitab Nehemia, } \\
\text { terbukti } \\
\text { kebenarannya }\end{array}$ & $\begin{array}{l}\text { Perlu } \\
\text { meningkat } \\
\text { kan } \\
\text { karakter- } \\
\text { karakter } \\
\text { yang } \\
\text { terdapat } \\
\text { dalam } \\
\text { kitab } \\
\text { Nehemia } \\
\text { bagi } \\
\text { hamba } \\
\text { Tuhan } \\
\text { sehingga } \\
\text { memiliki } \\
\text { kepemimp } \\
\text { inan yang } \\
\text { berhasil }\end{array}$ & $\begin{array}{l}1 . \\
\text { Mengad } \\
\text { akan } \\
\text { retreat } \\
\text { hamba- } \\
\text { hamba } \\
\text { Tuhan }\end{array}$ \\
\hline $\begin{array}{l}\text { Hipotesa Ketiga } \\
: \\
\text { Kategori latar } \\
\text { belakang } \\
\text { lamanya } \\
\text { melayani } \\
\text { dominan } \\
\text { menentukan } \\
\text { implementasi } \\
\text { kepemimpinan }\end{array}$ & $\begin{array}{l}\text { Perlu } \\
\text { meningkat } \\
\text { kan } \\
\text { motivasi } \\
\text { melayani } \\
\text { dengan } \\
\text { baik } \\
\text { dalam } \\
\text { kehidupan }\end{array}$ & $\begin{array}{l}\text { 1. } \\
\text { Menga } \\
\text { dakan } \\
\text { semin } \\
\text { ar } \\
\text { tentan } \\
\text { g } \\
\text { motiva } \\
\text { si }\end{array}$ \\
\hline
\end{tabular}




\begin{tabular}{|c|c|c|}
\hline $\begin{array}{l}\text { namba Tuhan } \\
\text { jang berhasil } \\
\text { perdasarkan } \\
\text { kitab Nehemiah } \\
\text { pagi kalangan } \\
\text { tamba Tuhan di } \\
\text { GKKI se Jawa } \\
\text { Tengah, dalam } \\
\text { penelitian belum } \\
\text { erbukti } \\
\text { kebenarannya. }\end{array}$ & $\begin{array}{l}\text { hamba } \\
\text { Tuhan } \\
\text { sehingga } \\
\text { memiliki } \\
\text { kepemimp } \\
\text { inan yang } \\
\text { berhasil }\end{array}$ & $\begin{array}{l}\text { melay } \\
\text { ani } \\
\text { 2. } \\
\text { menga } \\
\text { dakan } \\
\text { buku- } \\
\text { buku } \\
\text { refere } \\
\text { nsi } \\
\text { tentan } \\
\text { g } \\
\text { kepem } \\
\text { impina } \\
\text { n yang } \\
\text { berhas } \\
\text { il }\end{array}$ \\
\hline
\end{tabular}

\section{KESIMPULAN}

Para hamba Tuhan di GKKI se Jawa Tengah dalam mengimplementasikan Kepemimpinan yang Berhasil Berdasarkan kitab Nehemiah di Kalangan Hamba Tuhan di GKKI se Jawa Tengah cenderung cukup.

Para hamba Tuhan di GKKI se Jawa Tengah dalam mengimplementasikan Kepemimpinan yang Berhasil Berdasarkan kitab Nehemiah di Kalangan Hamba Tuhan di GKKI se Jawa Tengah (Y) cenderung cukup $(345,94-358,40)$. Para hamba Tuhan di GKKI se Jawa Tengah dalam mengimplementasikan Dimensi 1: Kepenundukan pada Otoritas Allah sebagai Exogenous Variable $\left(\mathrm{X}_{1}\right)$ cenderung cukup (39,68-41,38). Para hamba Tuhan di GKKI se Jawa Tengah dalam mengimplementasikan Dimensi 2: Komitmen sebagai Exogenous Variable $\left(\mathrm{X}_{2}\right)$ cenderung cukup (20,93-22,05). Para hamba Tuhan di GKKI se Jawa Tengah dalam mengimplementasikan Dimensi 3: Dalam Visi Allah sebagai Exogenous Variable $\left(\mathrm{X}_{3}\right)$ cenderung cukup $(27,86-$ 29,38).

Para hamba Tuhan di GKKI se Jawa Tengah dalam mengimplementasikan Dimensi 4: Memiliki Spiritualitas Tinggi sebagai Exogenous Variable $\left(\mathrm{X}_{4}\right)$ cenderung rendah menuju ke cukup (95,45-98,38). Para hamba Tuhan di GKKI se Jawa Tengah dalam mengimplementasikan Dimensi 5: Memegang Janji Tuhan sebagai Exogenous Variable $\left(\mathrm{X}_{5}\right)$ cenderung rendah menuju ke cukup (33,77-35,02). Para hamba Tuhan di GKKI se Jawa Tengah dalam mengimplementasikan Dimensi 6: Memiliki Kerendahan Hati sebagai Exogenous Variable (X6) cenderung rendah menuju ke cukup $(48,83-50,83)$.

Para hamba Tuhan di GKKI se Jawa Tengah dalam mengimplementasikan Dimensi 7: Mengandalkan Tuhan sebagai Exogenous Variable (X7) cenderung rendah menuju ke cukup $(30,40-32,09)$. Para hamba Tuhan di GKKI se Jawa Tengah dalam mengimplementasikan Dimensi 8: Pandai Dalam Strategi sebagai 
Exogenous Variable (X8) cenderung rendah menuju ke cukup $(47,77-50,50)$.

Dimensi mengandalkan Tuhan sebagai Exogenous Variable $\left(\mathrm{X}_{7}\right)$ sebanyak 92,2\% merupakan dimensi yang paling dominan mempengaruhi kalangan hamba Tuhan di GKKI se Jawa Tengah dalam mengimplementasikan Kepemimpinan yang Berhasil Berdasarkan kitab Nehemiah. Latar belakang jenis kelamin hamba Tuhan sebagai variable moderat $\left(D_{9}\right)$ kecenderungannya paling dominan berpengaruh terhadap mengimplementasikan Kepemimpinan yang Berhasil Berdasarkan kitab Nehemiah.

\section{KEPUSTAKAAN}

Barna, George. Kepemimpinan - Leaders on Leadership. Malang: Gandum Mas, 2002.

Eims, Leroy. 12 Ciri Kepemimpinan yang Efektif. Bandung: Kalam Hidup, 2003.

Gangel, Kenneth O. Membina Pemimpin Pendidikan Kristen. Malang: Gandum Mas, 1998.

Gordon, Bob. Visi Seorang Pemimpin. Jakarta : Nafiri Gabriel, 2000.

Harefa, Andrias. Kepemimpinan Kristiani. Jakarta: UPI STT, 2001.

Hasibuan, P. D. dan Susanti Embong Bulan. "Kepemimpinan Dalam Gereja Katolik Paroki Ignatius Loyola Dan Huria Kristen Batak Protestan Setiabudi Menuju Persatuan (Leadership In The Ignatius Loyola Parish Catholic Church And Setiabudi Batak Christian Protestant Church To Unity)." QUAERENS: Journal of Theology and Christianity Studies 1, no.2 (2019): 111-121. https://doi.org/10.46362/quaerens.v1i 2.5 .
Maxwell, John C. 21 Menit Paling Bermakna dalam Hari-hari Pemimpin Sejati. Batam Centre: Interaksara, 2002.

Oktavianus, Petrus. Manajemen dan Kepemimpinan Menurut Wahyu Allah. Malang: Gandum Mas, 1988.

Pardede, Pontas. Kepemimpinan Rohani. Surakarta: STT INTHEOS, 1991.

Rinehart, Stacy T. Paradoks Kepemimpinan Pelayan. Jakarta: Immanuel, 2003.

Sanders, J. Oswald. Kepemimpinan Rohani. Batam Centre: Gospel Press, 2002.

Soemarsono, Hariono. Tim dan Teamwork Plus. Bandung: Lembaga Literatur Baptis, 2003.

Strauch, Alexander. Manakah yang Alkitabiah: Kepenatuaan atau Kependetaan. Yogyakarta: Yayasan Andi, 1992.

Tim Penyusun Kamus Pusat Pembinaan dan Pengembangan Bahasa.

Tomatala, Yacob. Anda Juga Bisa Menjadi Pemimpin Visioner. (Jakarta : YT Leadership Foundation, 2005.

Widjaja, Imron, Bobby Kurnia Putrawan, Hengki Wijaya. "Manajemen Pendidikan Agama Kristen Melalui Pelayanan Penggembalaan Dalam Kelompok Sel." EDUKASI: Jurnal Penelitian Pendidikan Agama dan Keagamaan 18, no.2 (2020): 159-170. https://doi.org/10.32729/edukasi.v18i 2.689 .

Winanto, Natanael, Antonius Missa, dan Juan Ananta Tan. "Surat-Surat Pastoral Sebagai Petunjuk Praktis Penggembalaan Untuk Jemaat (Pastoral Letters As A Shepharding Practical Guidelines In Congregation)". QUAERENS: Journal of Theology and Christianity Studies 2, no.1 (2020): 44-61. https://doi.org/10.46362/quaerens.v2i 1.14 .

Wongso, Peter. Latihan Bagi Umat Allah. Malang: SAAT, 1992. 
Wursanto. Dasar-dasar Ilmu Organisasi.

Yogyakarta: Andi, 2002. 